\title{
ESCENAS DE LENGUAJE EN LA OBRA DE NICANOR PARRA
}

\author{
Pilar García \\ Universidad de Chile \\ pilargarcia.pg@gmail.com
}

RESUMEN / ABSTRACT

Ya en 1977, Cristián Huneeus señalaba que si a Poemas y Antipoemas de Parra corresponde Residencia en la Tierra de Neruda, ¿no sería del todo evidente la continuidad problemática de los artefactos en un terreno ambiguo entre la poesía y el objeto de arte, entre la poesía visual y la instalación? Bajo este marco de crítica, el artículo propone una lectura de Sermones y prédicas del Cristo del Elqui en diálogo con el giro que la crítica ha identificado en este momento de la producción poética de Parra. Esto queda a mi juicio relativamente mostrado en el problema del género que expresan los "sermones y prédicas" y las "Hojas de Parra", que Enrique Lihn referirá posteriormente a propósito de las 'hablas' que aparecen durante la dictadura y que la antipoesía asume, recicla e incorpora, en un más allá de la parodia.

Palabras clave: hablante antipoético, Sermones y prédicas del Cristo de Elqui, hablas y escenas, Hojas de Parra, escena de lenguaje.

In 1977 Cristian Huneeus noted that if Poems and Parra antipoems of Residencia en la tierra corresponds Neruda, would not entirely clear or obvious continuity or the problem of 'artifacts' in its ambiguous ground between poetry and art object, between poetry and visual installation? Under this framework I propose a critical reading of Sermones y prédicas del Cristo de Elqui in dialogue with the order or change that critics have identified at this time of poetic production Parra. This is my shown in the issue of gender expressing the "sermons and preaching" and "Hojas de Parra", that Enrique Lihn later refers about the 'tooks/speaks" that appears during the dictatorship and antipoetry assumes, recycle and incorporates them, in a beyond parody.

KEY WORDS: antipoetic speaker, Sermones y prédicas del Cristo de Elqui, talk and scenes, Hojas de Parra, scene of language. 
La crítica a la obra de Nicanor Parra ha consensuado un punto de término o de inicio para la parte segunda, o tardía de su obra poética, o para estudiar el carácter tardío de ese momento. Los Sermones y prédicas del Cristo de Elqui constituirían ese 'nuevo momento' o momento 'otro', que desde el punto de vista del desarrollo de su obra y desde el punto de vista de los diálogos epocales que la antipoesía entabla con las poesías y poéticas aledañas, de los años sesenta y setenta, constituye un punto de inflexión, precisamente en la figuración de un escenario -o más precisamente una escenificación-para la escritura poética. Quiero revisar en este escrito, considerando algunos horizontes epocales y referencias de producción poética contemporánea a los Sermones y prédicas, los nuevos momentos referidos o anunciados por el vate antipoético, pero más que como mensajes de función conativa, o de referencialidad poética, en cuanto momentos de apertura y captación de nuevos escenarios y escenas en que los nuevos -o inquietantemente antiguos-sustratos del lenguaje ocurrían, pero también, tomaban lugar. Esto, o digamos, esta proposición de lectura, es al mismo tiempo una manera de conectar en la teoría las materialidades en que devino la antipoesía, sobre todo visuales, objetuales. La refundación -y refundición- de la coloquialidad y del texto como hiperreferenciado, en una escenificación, es algo que marcaría gran parte de las poéticas líricas a partir de los años setenta en Chile, bajo los nuevos contextos culturales y políticos ${ }^{1}$. Podríamos entonces decir que algunos libros de Nicanor Parra a partir de este momento de 'ruptura' significan más bien o también libretos, objetos de escritura que ponen en discusión -o en alegato- su autonomía en cuanto textos de poesía lírica, o textos de escritura, aspecto que sí habrían alcanzado o habrían comenzado a alcanzar los poetas de la generación del sesenta $^{2}$. La antipoesía, en este momento, necesariamente permea otras fisuras y figuras de la lengua coloquial en su debate con las mediaciones. Algunos críticos han concordado en considerar la extraña lectura a que convoca Sermones y prédicas del Cristo de Elqui, y el eventual alejamiento de este libro de Parra de los anteriores, o en los casos más lúcidos, la pesquisa de la transformación del cambio de horizonte o del nuevo rumbo de la antipoesía ${ }^{3}$.

Advertencia preliminar, Schopf. De Parra a nuestros días. Santiago: Metales Pesados (Selección de Erwin Díaz).

Morales, Ambigüedad en la poesía chilena de la década del sesenta, Santiago: Cuarto Propio, 2012.

Desde el punto de vista de la modificación de las hablas y del yo poético, el momento de cambio ocurre con la instalación de una poética del discurso en Versos de Salón, 1964. 
Esto, ya a estas alturas y para nosotros resulta de cierta evidencia Chistes para despistar a la policía, Poemas para combatir la calvicie serían una suerte de constatación, o la puesta en escena de Mr Nadie, Mr Nobody. Los límites políticos y arriesgados de la poesía con la escena teatralizada, con los diálogos situados, describirían este nuevo momento, y creo que sería esta la manera de entender la función política de la poesía en los momentos de represión política. Las escenas de lenguaje que quiero describir tienen que ver con los hablantes hipostasiados, con los sustratos y sedimentos inaugurales de la escena cultural, fuertemente teatralizada, y con los espacios históricamente figurados por las hablas que la antipoesía recoge, rehúye y exorcisa de los usos demasiado recurridos del habla autoritaria y del habla de la tradición ${ }^{4}$.

Aquello que señalaría un punto de inflexión inscrito en la obra de Parra se refiere fundamentalmente al cambio de las coordenadas y condiciones en que debe ser leída, porque, uno de sus aspectos que para la 'contemporaneidad' define la obra de Parra y la lectura crítica instituida es que se trata de una obra que inscribe sus lecturas como poéticas, como indicaciones de lectura, o modos de recepción; actuales. Y los peligros de este momento anterior es que constituya esquemas de lectura demasiado rígidos de las poéticas posteriores o aledañas.

A pesar y más allá de las felices cronologías, o los intentos de cronologización de la obra de Nicanor Parra (Obras completas \& algo + ), lo que aquí nos interesa es el modo en que la denominada antipoesía adquirió otras fisonomías, en la resistencia al cambio de rumbo que las poéticas de los años sesenta ya habían anunciado para la poesía 'nueva', del cambio de época en el horizonte posmoderno de antaño ${ }^{5}$. Si bien la antipoesía ha sido en primer término crítico situada como una poesía posmoderna avant la lettre, lo cual permitiría autorizar su (ab)uso de los materiales tanto del pasado como del presente 6 , el horizonte de ruptura de la década del setenta instala a su vez a la antipoesía en un sitial podríamos decir con bastantes salvedades nuevamente paradigmático, o en una duda paradigmática. Podemos en este sentido leer la antipoesía posterior como una respuesta agresiva al ataque de las mediaciones, a los episodios

\footnotetext{
$4 \quad$ Ver Cultura y lenguaje, Zurita. Este es el escenario de la neovanguardia local con el cual comienza a dialogar Parra, ver tb. Galende, Cultura de los años ochenta.

Morales 2012.

Descrito en Schopf 2000, 2009.
} 
(de una cultura esquizofrénica, es decir, capitalista) ${ }^{7}$ y a la ampliación del escenario de batalla de la poesía, en una rehuida perspicaz posibilitada por las actuaciones sociales del lenguaje. En todo caso, y en el peor de estos, la antipoesía parriana a partir de los años setenta se convirtió en un audaz y a veces agudo diagnóstico cultural de un cambio o transformación que, ahora podemos ver, ningún mecanismo - que no fuese ajeno a la ciencia o a los fueros del progreso- estaba midiendo, pesquisando u observando; excepto en el plano de la experimentación ${ }^{8}$.

En este punto, la antipoesía tuvo sus principales observaciones respecto de sí misma y la, podríamos decir, observancia en las reservas al experimentalismo. La idea de tradición en este nuevo momento, en este momento otro, es problemática, y los registros que hará la antipoesía aparecen bajo el modo de un registro defensivo de los modos en que supuestamente se habría de conducir el arte o el lenguaje del arte. Bajo esta premisa, la relación entre antipoesía y escena de avanzada, para usar un término críticamente instituido y ampliamente empleado, es mayor de lo que pueda parecer, de la misma manera que observar de qué modo la poesía de las antinomias, por decirlo de algún modo, de los conflictos con el lenguaje, que no sería en sentido directo el caso de Parra, pero sí el de Lihn ${ }^{9}$, tendrían ese sitio durante estas décadas, por tratarse sobre todo de poesía de escenificaciones /y de escenificadores/. Y, en sentido problemático, de escenificaciones del lenguaje.

\title{
EFECTOS DEL DISCURSO
}

Es el problema más importante en la antipoesía; este intento de definición o de redefinición de las nociones de discurso detrás de la antipoesía ha alcanzado relevancia en la crítica reciente a su obra (Gottlieb, Binns). La sustitución de un tipo de lenguaje o la composición del poema a través de capas de lenguaje generaría un efecto de acumulación de discursos que eventualmente son organizados por el antipoeta y activados como posibles sentidos actualizados por el lector. En primer término, la relevancia de la noción de discurso compuesta, y podemos decir, articulada por su obra,

\author{
Deleuze, Antiedipo. Capitalismo y esquizofrenia. \\ Zurita, Bruner. \\ Foxley; Contra el canto de la goma de borrar, Noguerol.
}


implica la idea de nuevo lenguaje en cuanto discurso situado, resultante de la composición. Los artefactos, en la disolución no solo del poema -en la visualidad- sino del libro, como señala Leonidas Morales, muestran esta condición de novedad, inscrita en la práctica antipoética; en la cuestión de los enunciados de discurso en el uso del poema (verso libre como frase hecha, por ejemplo). En tal sentido, el poema, es un constructo de lenguaje pero de carácter objetual; el poema adviene objeto y se instala como indicio y señalización de una nueva condición de producción y de lectura.

Es por ello que desde el punto de vista discursivo, el rasgo más relevante que manifiesta la antipoesía ocurre en la instalación contextual o situada de los dichos del antipoeta ${ }^{10}$. Si uno de los caminos innegables y efectivos de la antipoesía ha sido la visualidad, el despliegue visual, en una alegoría posmoderna -donde podemos pensar al antipoeta como un alegorista posmoderno- la otra dimensión que advierto y sobre la cual el artículo intenta profundizar relativamente, es la de la construcción discursiva dramática, escénica o teatral del antipoema en cuanto poema situado y aparato de carga política potencial. Es desde aquí que desplegaré algunos conceptos vinculados a la noción de discurso que no utilizaré como tal, sino que como escena de lenguaje, que espero ocurra apropiada para la ubicación de ciertas coordenadas de la antipoesía siempre en los estratos límites de la producción poética. No hay solo aquí estructuras discusivas (formaciones) como el monólogo dramático o tipologías (Foucault) como el soliloquio, sino lo que quiero proponer como hablas, atendiendo probablemente no tanto a la distinción saussureana de 'langue et parole" ${ }^{11}$, sino más bien a la distinción narratológica entre voz y habla, o más bien, entre voz y parlamento, en el cumplimiento de esta proposición desde la teoría del drama $^{12}$. La escena de lenguaje será por tanto la instalación del antipoema en las condiciones de referencia que el poema, el antipoema, cifra y borra, actualiza y desplaza. La genealogía de este modo de aparecer del antipoema puede ser rastreada a partir de poemas como: "Mil novecientos treinta"13. En este poema es ensayado o experimentado un tipo de hablante poético con

10 Gran parte de las últimas publicaciones de Nicanor Parra corresponden a los discursos pronunciados por el autor.

11 Curso de lingüística general, traducción de Amado Alonso.

$12 \quad$ Fischer-Lichte 1998.

13 Aparecido por primera vez en 1969, dentro de Obra Gruesa. También en Nicanor Parra, Antipoems: New and selected, New Directions, 1985, Interesa destacar cómo en esta edición bilingüe "El hombre imaginario" aparece traducido como "The Man He Imagined", 
todas las características del sujeto de la postvanguardia, primero, un sujeto que no es ya sujeto, "Yo sólo soy una cámara fotográfica que se pasea por el desierto" 14 , luego, en una evidente correlación imposible con las "Alturas de Machu Picchu" de Neruda, el hablante antipoético instala a la historia como un relato que puede ver, que puede experimentar y ser escenificado: "Veo como el viento los rechaza varias veces al punto de partida [...] Veo a algunos de ellos resbalar y caer al abismo" (38), y el hablante antipoético es situado en un lugar de visión y ausencia, un hablante poético expuesto y ajeno a aquello que narra. "Miles de terroristas croatas y eslovenos son ejecutados en masa a mis espaldas / Yo dejo hacer, dejo pasar" (39).

Lo primero de ello es advertir la línea de continuidad entre este tipo de antipoemas de carga semántica distinta a la versificación endecasílaba de los poemas que aluden a tópicos o a modos de la tradición poética, inmediatamente anterior, en el plano de las influencias (Binns). Son estos poemas, que a mi juicio corresponden a otra salida, a otra modalización, ya no simbólica, sino alegórica del discurso que el antipoeta, que la antipoesía se encuentra representando. Un tipo de construcción o probablemente configuración (Pareyson) discursiva del poema que posteriormente realizaría de manera objetiva y perceptual Gonzalo Millán en libros como La ciudad. Ese estado de existencia y suspensión del referente es lo que articula el mundo del poema. Mundo, dicho, no está de más indicarlo, acontecido de manera bastante literal, o concreta, a partir de la referencia a la historia, o modos históricos, que Parra nuevamente toma de la prensa. Esto ocurre casi en su completitud en un texto tardío, y de reciente publicación: Temporal, libro publicado por las ediciones de la Universidad Diego Portales, el año 2014. El motivo es ecdótico, e instala nuevamente al antipoeta como operador del lenguaje en una distancia o punto de hablada que es un punto cero del discurso (Schopf 2004).

esto es, 'el hombre imaginado', y es más, 'el hombre imaginado por él'; una traducción que nos parecería hecha por Enrique Lihn.

14 "Soy una alfombra que vuela / Un registro de fechas y de hechos dispersos // Una máquina que produce tantos o cuantos botones por minuto // Primero indico los cadáveres de Andree y de sus infortunados compañeros" (38). Asimismo, en este poema, la similitud de poéticas entre Parra y Georg Open es evidente. Tomado de Nicanor Parra, Antipoems, 1985, ver también, Open, G. 


\section{SERMONES Y PRÉDICAS}

La pregunta es cómo entonces ocurre el despliegue propiamente teatral, escénico, visual, de esa especie de épica -épica de un teatro pobre- del personaje, actor y figurín, del Cristo del Elqui, que continúa llamando la atención de sus críticos (Schopf, Zambra).

La escena teatral es una escena compleja en la que acontece una innumerable serie de elementos, que es propio de la semiología el estudiarlos y dar cuenta de ellos (Fischer-Lichte, Pavis). Lo que queremos definir, identificar, desde los poemas panfletos, poemas parlamentos, poemas diálogo, poemas monólogo, poemas dramáticos, los libretos de las "Hojas de Parra", las hablas coloquiales (CEP) es cómo se constituye esta escena, que no teatral -si bien a los críticos les guste mucho esta faceta de Parra y de la vida de Parra- sino de lenguaje. En este sentido, la pregunta por cómo una escena es constituida en cuanto escena es lo que articula estos sermones y prédicas, trasladados al estatuto de antipoemas. El carácter de manifiestos de esta condición de escena del lenguaje queda explicitado en "Soliloquio del individuo" y en "El hombre imaginario" $"$. En una lectura inclinada con la tradición del teatro chileno de los años 80, la antipoesía instala una contralectura, y es allí donde ciertos puntos de hablada se diversifican: entre la poesía propiamente visual en la independencia o autonomía del artefacto, mencionada por Schopf, y la antipoesía de la escenificación o que se presta para ello ${ }^{16}$.

Cualquier término, cualquier palabra daría pábulo al actor para pronunciar el parlamento ${ }^{17}$.

La constatación de autorreferencia del antipoema como aparato de lenguaje se instala desde estos poemas; el hablante poético escenifica el poema, escenifica el discurso del poema, frente a un sí mismo que busca distanciar al operador del lenguaje de quien emite el discurso, o enunciante poético. Me parecen notables las lecturas a estos poemas de Nicanor Parra, cuando destacan su carácter retórico, discursivo, de qué modo generan sistema dentro de la empresa antipoética, y cómo estos poemas aparecen anclados, rasantes a sus contextos socio-históricos. Ver: Alonso, nuevamente Schopf, también Binns, vid Grossman.

16 Desde una revisión de las formas estéticas y de modelos artísticos, me parece que este momento la obra de Parra tiene elementos comunes con la del dramaturgo Juan Radrigán, por sobre todo.

17 En este punto, la discusión que sostiene Morales sobre la antipoesía y su relación con la sociedad del espectáculo, parte de esos estratos de experimentación del poema, de la antipoesía, con la publicidad, con el lenguaje de la prensa, con la llegada y la conmoción social 
Como digo, el monólogo dramático en Parra (Gottlieb, Zambra) describe un estado discursivo de los antipoemas, como instalación de esa otra voz, una voz en off, o de esa voz que no le habla particularmente a nadie (alocucionaria) si bien existe un receptor hipostasiado - una galería imaginaria, el pueblo-. Es así entonces que la variante entre voz y habla genera esta diferencia o contaminación entre la ejecución del antipoema y la constitución anterior de este en libreto o parlamento. Esta es una cuestión que es tarea de otras disciplinas científicas, y que tiene que ver con el problema de la genocrítica de un lado, y de lógica simbólica de otro, en lo referido a cómo funcionan los textos respecto de la producción, literaria, artística, poética, del propio autor ${ }^{18}$. El problema de los 'borradores' en Parra, convertidos en obra constituyen otro tema ${ }^{19}$ que nos hace pensar en la calidad y cualidad de parlamentos de muchos de sus poemas, que ya son instituidamente leídos como tales. Así, vertiginosamente, estos modos o modalidades del discurso que Leonidas Morales quiso destacar cuando entrevista a Parra (trabajo con la edición de Tajamar 2006, ver página 13) pueden ser aplicados para los antipoemas constituidos en libros, en publicaciones -no diremos, antilibros, para no complicar metodológicamente la exposición-: chistes o informes que entrega Parra, como en el caso del temporal que azotó a la ciudad de Valdivia en 1987, y que da lugar al libro Temporal (Parra 2014).

En este sentido, el problema de las voces para el poema, el antipoema, es distinto que para el teatro. No es solo el problema de las voces, o el problema de la "esquizofrenia", que la poesía aborda necesariamente a partir del mecanismo de la mímesis, en que el problema de las voces, poéticas o no en la poesía es un problema mimético, es el caso de Eliot. El problema de las voces, el teatro lo resuelve de manera distinta a la poesía, es esa una de las encrucijadas que propone la antipoesía en este periodo cuando se propone escenificar el antipoema en la figura del Cristo de Elqui, en que los textos son de algún modo constreñidos a la lectura poética como lectura del poema ${ }^{20}$. Si comparamos o confrontamos Sermones y prédicas del Cristo de Elqui con Versos de salón observamos que en el libro de 1971 hay visión de

que provoca el lenguaje inmediato de la publicidad y de la prensa, así como sus reacciones (Morales 2014).

18 Teoría literaria, Marc Angenot 2011.

19 Ver Soto, C. CEP, 2014.

20 La pregunta, por cierto, es qué es la lectura del poema, sobre todo cuando los teóricos más contemporáneos -y no necesariamente posmodernos- han declarado que la lectura del 
mundo, interioridad, o representación de la interioridad, aunque sea expuesta como falsa, el operador antipoético interviene de distintas maneras en los efectos de corte o de escisión, para constituir partes, en las intervenciones y pensamientos (visión de mundo) del Cristo. En un sentido opuesto, o extremo, las intervenciones del operador antipoético suponen la disolución de toda interioridad prevista en la exposición e intervención del Cristo de Elqui. Las coordenadas que sitúan a este personaje de los años treinta en la década del setenta son los espacios de integración reconocidos socialmente como el programa Sábados Gigantes. De esta manera, cuando el operador hace hablar al Cristo en los diversos escenarios 'históricos' que transita, desaparece esta condición histórica y el discurso es poblado por las hablas. Hablas que pertenecen más bien al sustrato epocal del momento histórico en que es situado el personaje: la dictadura.

La confrontación caótica de discursos deben ser asumidos por una voz o, más bien, por un personaje - a mi juicio, más que enmascarado, desprovisto de cualquier máscara-, entregado a la suerte de estas escenas y los discursos con que estos espacios parecen bombardearle. En este sentido, el hecho de que cohabiten en un mismo espacio -recordemos que en el Cristo de Elqui se trata de un personaje del pasado histórico-discursos heterogéneos, modificando la relación que el antipoema ya había establecido con el afuera del poema en Versos de salón y particularmente en Artefactos, supone una de las características indicadoras del drama contemporáneo ${ }^{21}$. Este efecto se produce porque "Parra crea un personaje y lo deja hablar directamente al público, sin ninguna intervención por parte del poeta" (Gottlieb 1996: 73), cuestión que caracteriza la constitución de la noción de escena.

Así, desde la visión del antipoema como potencial y declarado libreto sería interesante preguntarnos cuáles son las didascalias, las acotaciones, los aparte, del conglomerado de hablas antipoéticas. La antipoesía formularía el problema de las voces en las escenas, en cuanto escenas sociales, en primer término. Y el problema de las voces es el problema del sujeto poético enfrentado a la escena social.

¿Qué elementos hay del hablante, hablador o parlanchín antipoético de Sermones y prédicas en el "Soliloquio del Individuo", en "Advertencia al

poema es algo así como un no posible, desde la estabilización de la metáfora, y la estabilización tropológica en general (Vid, Culler, La poética... y también Cohen, El lenguaje...).

21 Pavis, P. “El juego de la vanguardia teatral y la semiología”. Lom, 1998. 
lector", o en poemas como "Hay un día feliz". El problema de la genealogía/ archeología del antipoema es constituida o aparece ad libitum, de alguna manera la crítica ha señalado que la antipoesía es una escritura genealógico/ archeológica por definición (Schopf), o sea, problemática con o respecto a los sustratos ahí desenvueltos o desencadenados o suficientemente recluidos. Pero la voz disruptiva puede hallarse en las nuevas formaciones críticas del verso libre, o la conciencia de libertad del verso, y las nociones de ritmo en gran parte dependientes de la '(s)in-tonización' con las hablas y las escuchas coloquiales -que dicho sea de paso, también preocuparon a José Donoso durante el periodo ${ }^{22}$.

Es en cierto modo este un problema de derivación, que señala Huneeus en una conferencia que relaciona la poesía de Parra con la de Neruda, y en donde manifiesta una interrogante respecto a la 'derivación' de los artefactos, en cuanto objeto raro. Y esto es, más que objeto encontrado -trouvé- se trata de objeto hecho, manufacturado o construido, operado, hecho obra, convertido en objeto in-últil.

La decodificación de las hablas, así como la superposición de máscaras lingüísticas que encubren, protegen o aseguran esta operación pueden describir la figura del predicador; máscaras que son despojadas en la escena. Esto es similar en el Pompier de Lihn, y en este caso. El antecedente de esta ruptura, en cuanto cambio estético en la antipoesía de Parra, que podríamos definir entre el subgénero mixto de sermones y 'artefactos', se encuentra en el Quebrantahuesos, que dicho en varios sentidos es una práctica de avanzada en el recorte, recopilación, composición, montaje de mensajes, de cuyo resultado no sería en ningún caso responsable el/los operador/es. El punto singular iniciado por el Quebrantahuesos es el de la destrucción de la poesía como ejercicio surrealista y como marca de los tiempos nuevos de entonces. Volviendo sobre la idea de las hablas. En la antipoesía, o en el proyecto de una escritura antipoética, las voces devienen hablas ${ }^{23}$; son conducidas por un sujeto. Las competencias lingüísticas y referenciales de la antipoesía respecto a los medios y a las mediaciones posmodernas la sitúan en una encrucijada con respecto a las hablas, ahora diversificadas. Si pudiéramos decir de alguna manera, la poesía parriana antes del experimento del Quebrantahuesos,

23 Binns propone algo correlativo en su lectura de Versos de salón, en que como efecto de los mass media y de los ritmos urbanos, "el yo poético se fragmenta y su voz de individuo se disuelve en un delirante collage de voces e imágenes ajenas" (2014: 158). 
y también antes de los sermones, es una poesía no representativa, ni en el sentido institucional del término ni en su sentido filosófico-estético. A partir de Sermones, leemos una poesía representativa, en el sentido vulgar del término, que irrumpe desde la intervención surrealista e iconoclasta del Quebrantahuesos: "Padre estranguló a su hijo como medida disciplinaria" 24 . Una poesía de la puesta en escena, exhibitiva o, más bien, que exhibe a un hablante y a una voz en el espacio social.

Son, en este sentido, diversos los términos, los conceptos que entran en juego, e inciden en una definición, un modo de entender la antipoesía. La noción de escena como concepto epocal en su redefinición en la década de los sesenta, y la apertura de este concepto proveniente de la década anterior. Es en este sentido que Parra se convierta o se transforme en un poeta que pueda ser leído desde las artes visuales, desde la teatralidad, desde la puesta en escena y la performance, como ocurrió de manera evidente con la recepción de la poesía y las diversas manifestaciones artísticas de Enrique Lihn, que se relacionaban con su obra poética. Y que actuaban como contrapunto o complemento a estas manifestaciones singulares en su prosa, el teatro, el comentario de arte.

Morales se refiere a la publicación de poemas y antipoemas como un gesto crítico de ritualización (148). Espectacularización de la recepción de su poesía, en el énfasis del humor y del lenguaje coloquial. Hace una distinción entre escritura antipoética y proyecto antipoético, en que el proyecto antipoético habría concluido mucho antes que la escritura antipoética (149). A ese nuevo momento se superpone la idea de escenificaciones que, como señalaba, ya inicia tempranamente en el Quebrantahuesos ${ }^{25}$.

24 Habría que pensar, en este sentido, hasta qué punto el Quebrantahuesos llamaba a una lectura seria o diluía la recepción festiva promovida por la prensa y los anuncios. "Voló tren en Paine", "Vendo por luto novio roto no funciona", "Durante 18 días una niña durmió en un nicho junto a un tarro de dulce de batatas", o "Alza del pan provoca otra alza del pan", pero sobre todo, cómo debían o podían ser leídos. Recordemos lo que decía Jorge Teillier: "Nicanor Parra afirma una cosa que es muy rara. Dice: yo cultivo el lenguaje de la tribu. Pero hablar el lenguaje de la tribu es hablar en el lenguaje de roteques. A mí no me interesa la tribu. La tribu es la de los orangutanes" (Olivárez, Conversaciones con Jorge Teillier, 1994: 91).

25 Ver en el "Prólogo" de Tomás Lago, la descripción de aquella inocencia de la palabra, del decir originario, confrontado a los hallazgos de la antipoesía en un nuevo contexto, este contexto nuevo no es aquel del campo o de la aldea, problemática sobre la cual Parra volvió en su poesía de manera casi insistente, en Viaje al infierno, o en las constantes diversificaciones métricas. Pero es este el punto, cómo la poesía de Parra enfrenta al nuevo tiempo, el momento 
"En la tercera etapa del proyecto, la de los Sermones y Prédicas del Cristo de Elqui y los Nuevos Sermones y Prédicas del Cristo de Elqui, el personaje retoma su continuidad como sujeto de la enunciación, y su palabra vuelve a ser la palabra de un discurso. Pero ya no son los mismos que fueron en la primera etapa. La provocación, la autocomplacencia en el gesto negador, el entusiasmo y la soberbia quedaron sepultados en el acto de la negación de la negación" (Morales 2012: 166). Para el autor, en este último momento no habría confrontación.

La postmodernidad en Parra (Binns 2014) aparece más bien a través del problema de las voces, de los sustratos profundos y muchas veces contradictorios de la enunciación, que de la imagen. Que en el caso de Parra es más bien una imagen discursiva.

Las voces de la escena. La escena poética es escena lingüística, el poema funciona o será tal a través de una sustitución o trasposición de voces. Los tópicos del poeta, la voz como operación de voz - voces, irrumpe en un escenario otro.

Deslindar la noción de postvanguardia tiene que ver en el caso de la antipoesía con la modificación de la imagen poética -y lo que era entendida por tal-, de su condición discursiva; de qué ocurre con la metáfora para la tradición lírica, en este caso, la percusión del antipoema como chiste, anuncio publicitario y los límites que este entramado constituye, asimismo la influencia de los espacios en que se instala el habla antipoética en cuanto espacios y lenguas, hablas y nomenclaturas, de lo postmoderno, llegando de alguna manera la antipoesía a definir ciertas pautas de la postmodernidad poética (ver Morales, Binns). En que el poema ya facultado a convertirse, a ser, efectivamente, a ser experimentado como otra cosa: como un artefacto visual, pero particularmente alegórico, recordemos que la alegoría, el objeto

histórico otro, cómo es o fue desde sus inicios una poesía no de la vanguardia, sino de la postvanguardia, debiendo con ello asimilar los formatos de la producción del poema a esos nuevos y aparentemente otros escenarios -otros en apariencia- en la dislocación del lector, instado por la lectura de cierta práctica de la lectura antipoética. Aquí hay dos puntos centrales mencionables, el de la poesía situacional y el de la poesía visual. El prólogo de Lago a su antología sin duda atrae o convierte en una constante crítica el problema de las influencias y de las refundaciones o modificaciones del canon, la celebración del "hallazgo expresivo", en cuanto "sedimentación del campo poético" a contrapelo de lo que habrían fijado -pero quizá fijado demasiado- los poetas fundadores de la poesía moderna en Chile (Cruchaga, Huidobro, Neruda, De Rokha). El problema del lector "no iniciado" en los temas de la poesía vanguardista es lo que dice Morales, sería el punto de interés de este primer momento parriano, según Lago. 
alegórico resiste por la conexión, la voladura provocada por el mensaje que confirma o que en muchos de los casos contradice aquello indicado o sugerido por la imagen, el carácter contrastivo de la frase que configura el artefacto señala, advierte, varios niveles de la lectura y de problemas de evanescencia del mensaje o del probable mensaje del artefacto, que continúa o que se permite continuar bajo cierto estado de enigma (nota poesía visual de los años sesenta).

Por otra parte, el marcado carácter lúdico, libretesco, performático, teatral, que adopta la antipoesía a medida que avanza la década del ochenta tiene que ver con la directa transformación del sistema productivo de la antipoesía, cuestión de suma importancia destacada recientemente por la crítica que identifica etapas en el proyecto antipoético de Parra (Morales 2012). El ensamblaje y la posibilidad de existencia de la antipoesía en estos otros registros, pero en cuanto antipoesía, permite esbozar algunas hipótesis sobre el momento de una forma poética altamente productiva en transformación. El carácter desfachatado y Dadá que experimenta la antipoesía en este periodo, que es también denuncia y tabla de salvación. Mostrando o trazando una interesante integración histórica y contextual con los escenarios históricos y artísticos del Chile de la segunda década de represión dictatorial. Este suministro de códigos de lectura, en una versión que con el paso de las décadas hemos visto grotescamente amplificada, sucede en la década del ochenta en que la instalación aparece como fuero de lo antipoético. Pues la dimensión satírica no estuvo ajena a las intervenciones del mismo Parra en Viña del Mar el año 1989, con la asistencia del presidente Patricio Aylwin, con un Parra que tal como lo hiciera en los años setenta, señalara que en Chile no hay más hospitales porque no hay más enfermos. De este modo, las dobles connotaciones marcarían el tránsito de los antipoemas a artefactos y a libretos, folletos o proclamas (ecopoemas, poemas para..., chistes directamente) en un gesto dadaísta de ubicación de horizontes históricos. Cuestiones de orden simbólico que explican por qué sin Parra no serían posibles poetas como Diego Maquieira. Estos señalamientos de orden estético sitúan los espacios y los narradores -hablantes líricos, sujetos poéticos- de Parra como voces que convergen en el poema adecuando escenarios y entablando diálogos en escenas sociales creadas y recreadas por el antipoeta: la sala de clases, el Paseo Ahumada, el regreso a la aldea.

La escena poética es escena lingüística, y al antipoeta le ocurre lo que José Emilio Pacheco identifica en los paseos de Lihn: "Lihn describe el mejor poema que se ha escrito hasta hoy contra el neoliberalismo y sus consecuencias, 
Paseo Ahumada. Es, voluntaria, paródica e insultantemente, el Canto General de los vendedores ambulantes, los desempleados, las víctimas del progreso, que llenan nuestras ciudades con 'los artificios naturalizados en Taiwán, La Gran Madre Plástico' que nos inunda con 'sus dejecciones y babas'" 26 (53). Esta visión en contraste entre la experiencia del Paseo Ahumada, como asidero indeseado del poeta, como lugar de escucha, de paseo, de visualidad, como lugar de 'dejección', y en el caso de Parra, intento de experimentación, o de prueba con las lenguas que se hablan- no solo de la 'tribu', no solo la lengua de las nuevas modernidades, como la de la tv, sino una lengua que retiene una extraña resonancia para el antipoeta (Sermón IV: "No se diga que soy un pordiosero / quién no sabe cómo me he ganado la vida / en estos 20 años que duró mi promesa / giras al sur y norte del país / como también a los países limítrofes / predicando mis sanos pensamientos / en beneficio de la Humanidad". Sermón XI: "Un agregado de última hora: tan pronto como se me apareció el Señor / tomé un lápiz y una máquina de escribir / y me puse a redactar mis prédicas [...] Distinguidos lectores: en estos momentos / os estoy escribiendo en una enorme máquina de escribir / desde el escritorio de una casa particular / eso sí que ya no vestido de Cristo"); el poema funciona, o es tal a través de una sustitución o trasposición de voces en hablas. Los tópicos del poeta, la voz como operación de voz-voces, irrumpe en un escenario otro. Difuminado por las actuaciones, las intervenciones del Cristo, hablador, ambulante o profeta.

En este sentido, los rasgos que en algún momento caracterizaron a la lírica moderna ya corresponden a rasgos de la descripción postvanguardista de la frase hecha o lugar común. El espacio, el lugar de escenificación del lugar común como hablas, que pueden decir lo no dicho por el discurso de la norma y del orden (Foucault), que pueden revivir el lenguaje común prosaico, como en la poesía de la claridad, muestra también y ahora, en este nuevo escenario, las hablas hipertrofiadas; como residuos de una tradición oral. La conversión de esta tradición oral residual en "palabra poética" es el primer problema que debe enfrentar-y eventualmente resolver- el antipoeta en la configuración de esas -nuevas- escenas sociales: "Señoras y señores: con ustedes el Cristo de Elqui en persona".

26 Pacheco, José Emilio. "Menosprecio y alabanza de la poesía”. El espíritu del valle, 2-3, 1987. 


\section{"HOJAS DE PARRA, SALTO MORTAL EN UN ACTO"}

La historia de las "Hojas de Parra" es ya a estas alturas un metarrelato, caído, precisamente, en el periodo de la dictadura ${ }^{27}$. La obra recrea el momento de la exposición pública durante la dictadura, llevada a escena en 1976. Esta ley de excepción que llevó a cabo la representación de la obra entabla diálogo con los códigos sociales imperantes, desenvolviendo una estrategia contraria a la autoridad, a la vigilancia y el castigo de los modos de control durante la dictadura.

La historia de la quema de la carpa. La obra es presentada en tres funciones, con Jaime Vadell que toma los textos de Parra y los integra en un diálogo teatral. Esta historia o contrahistoria que cuenta la antipoesía en el momento de oscuro declive de la dictadura es aquella que solo puede contar el texto -el libreto mecanografiado- $y$ el relato o testimonio fragmentariamente restituido de sus participantes, y que toma los contextos codificados por los Artefactos y los Sermones.

Los cuadernos de Parra circularon en los ambientes más lábiles de la vida cultural y artística de los años de dictadura. De alguna manera, la traducción de Parra del Rey Lear de Shakespeare (Lear \& Mendigo, de Parra) es un habla continuada de lo que ha ocurrido en la práctica de la antipoesía con las "Hojas...". A mi juicio, constituye parte de la relevancia que debe ser señalada en la historia del teatro chileno durante la dictadura, parte de esa historia que reconstruyó para el teatro el Teatro La Memoria, dirigido por Alfredo Castro. Esa es la línea de continuidad regresiva que, desde mi punto de vista, tomarían las "Hojas...".

En un texto del crítico y poeta -pero también dramaturgo y dibujanteEnrique Lihn, aparece un diagnóstico, socioartístico del periodo de la dictadura. El autor describe el momento como de dislocación o de descolocación política, por una parte, pero también, y casi diríamos por consiguiente, de desajuste de las conciencias o de las interioridades, ¿de las subjetividades?,

$27 \quad$ Los actores Jaime Vadell y José Manuel Salcedo, luego que se separaran del Teatro Ictus, forman en 1976, la compañía de Teatro La Feria. La obra "Hojas de Parra, salto mortal en un acto", de Vadell y Salcedo, basada en poemas de Nicanor Parra, es presentada en febrero de 1977, en la Carpa del Circo del Teatro La Feria en el Parque Providencia y en marzo es incendiada por desconocidos. 
que él llamará bloqueamiento ${ }^{28}$. La discordia o discordancia que observa y percibe el artista en estas fases y momentos de un proceso social traumático es el del bloqueo. La idea de bloqueamiento muestra a mi juicio de qué modo Lihn vio por sobre los años, por sobre algunas décadas, la germinación de las estrategias del mercado que se instalarían con posterioridad luego de la transición. El bloqueo de la cuenta, el bloqueo de la tarjeta es en este caso, en su descripción, un bloqueamiento mental, síntoma que afectaría al entramado social en su completitud.

La obra mezcló elementos del clown y del absurdo, generó el espacio, el ambiente de la carpa. Probablemente por indicaciones de las didascalias, el circo era utilizado, a su vez, como espacio significante, y no era obliterado o suspendido, como ocurre en la representación del realismo.

Cuando la antipoesía habla, decimos, de un Chile, lo hace desde la captación de estas hablas sensibles, percibidas por el operador antipoético. Esa otra línea, la línea dramática de la antipoesía pertenece al más representativo modelo del teatro anarquista o de denuncia, que practicaron los grupos teatrales chilenos contrarios al régimen dictatorial impuesto. Esa capacidad de habla de la antipoesía, no sólo desde la visualidad - que no es el tema que nos ha preocupado en este estudio - sino el de la escenificación, muestra dos de los principales frentes que la antipoesía desplegó en la defensa y la resistencia ante la inminente transformación del mundo, como han dejado ver sus críticos. Sin duda la evidente capacidad teatral y lúdica de la antipoesía, ya destacada por sus críticos -Buck Morss, Gottlieb- es el punto en que la antipoesía rearticula desde escenarios significantes el problema del lenguaje y de la poesía. Ese es sin duda otro de los esfuerzos de Parra como pensador o experimentador del lenguaje, una fórmula química como lenguaje de la denuncia. (Imagen 1. Hojas de Parra, 1977, fotografía de Hans Ehrmann).

28 Es interesante desde el punto de vista lingüístico, pues la narrativa surgida en los años ochenta intentó dar nombre, a este estado o sensación, bajo la idea, por ejemplo, de 'mala onda', de 'lumperismo'. Y esto muestra también de qué manera Enrique Lihn pertenecía a otro tiempo. Enrique Lihn (2011). 


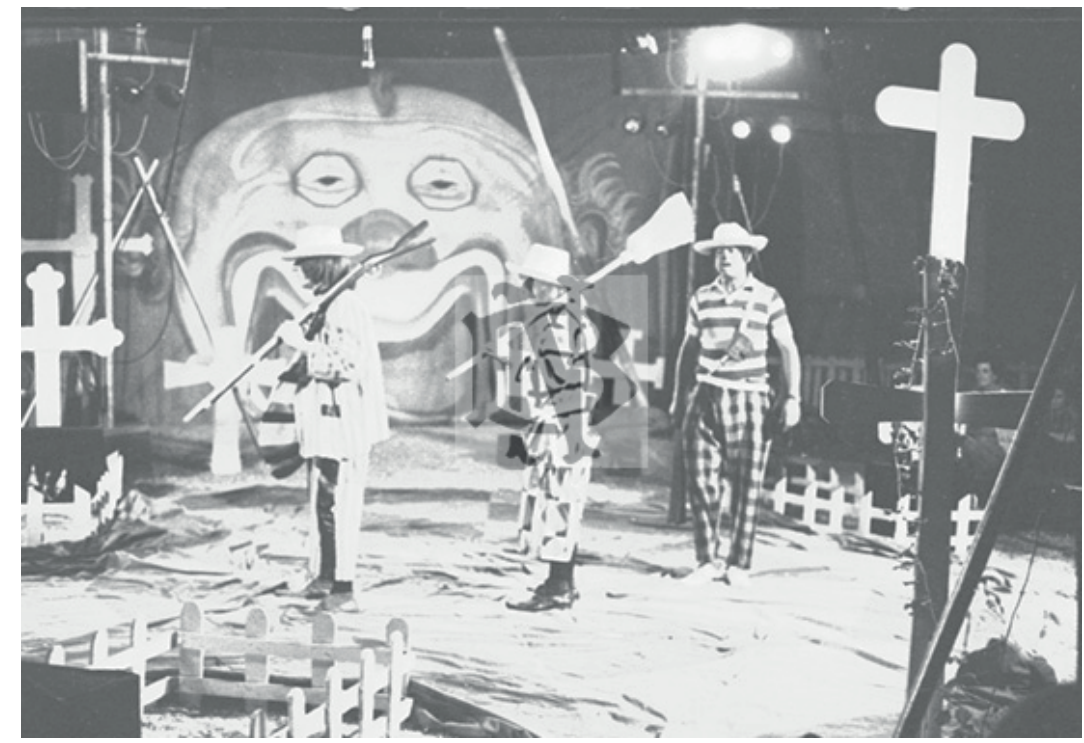

Imagen 1

La antipoesía mostraría la movilidad y también la inmovilidad de los referentes poéticos en confrontación con los referentes políticos institucionalizados. Como dice F. Schopf: "en este sentido resulta decisivo que la aparición, en los antipoemas, de lugares comunes de la expresión y del sentido común esté reorientada hacia referentes diversos que sus referentes normales, institucionalizados, produciendo en el lector, así el efecto inesperado a través de lo familiar" (11). Esto Schopf lo redefine como un efecto de shock, en otro estrato: la vanguardia buscó el shock en la exteriorización de la escena social, pública, en la escena y sus niveles de obscenidad o de exposición exhibitiva -su carácter último-. Mientras, Schopf redefine el shock postvanguardia desde la antipoesía como conmoción en o desde lo familiar y lo cercano, cuestión que correspondería a una redefinición de la función política del arte en este periodo.

Esa es la operación que marcaría o definiría esta transformación de la antipoesía: en la materialidad. El estatus del libro es radicalmente otro, llevando en cierto modo esta hipótesis a un terreno aledaño, cuando pensamos los antipoemas de Parra como o advenidos 'libretos'.

Hay algunas ideas que parecen definidoras para tratar este nuevo estado, este estado otro de la antipoesía: sobre todo en lo referido a que se enfrentaría 
a la "condición anestesiada" de sus "potenciales lectores" (12), frente a las voces y las experiencias lingüísticas codificadas y configuradas por un periodo histórico.

En el experimento de los Sermones y prédicas y en las "Hojas de Parra" y salto mortal en un acto, el personaje se construye como una categoría lábil, asumida no solo por el actor, sino también por un espectador ${ }^{29}$ ya adiestrado en recursos de la tradición literaria, como tomar un hablante, un personaje, hablar por la voz de otro.

Dentro de la obra de Parra, Sermones y prédicas del Cristo de Elqui inauguran un sistema de enunciación en el modo cómo se vuelve y se transforma en una poesía escénica. Y de qué manera hay relaciones de continuidad -y ruptura- en la composición del antipoema.

En el contexto de la dictadura, la postmodernidad aparece a través del problema de las voces, de los sustratos profundos y contradictorios de la enunciación (hablas / interlocutor) en lugar de la imagen. Las voces de poema son las hablas de la escena poética lingüística.

Señalado por Schopf en otros momentos: "la antipoesía -o una parte de ella- ha mostrado, por su parte, una sorprendente capacidad de recuperar su sentido o reorientarlo en medio de lo vertiginoso y en apariencia caóticas transparencias de los contextos en que, en la actualidad, tiene lugar la recepción de la literatura" (id.), en el modo cómo reactiva, en un contexto que el propio antipoema rechaza, el problema de los lenguajes, las hablas, de la dictadura.

Bajo el escenario del arte contemporáneo, en que la antipoesía es un reducto de la visualidad y de lo teatral, podemos citar a Jameson cuando dice, a propósito del collage y la diferencia radical, que: "La propia crítica norteamericana reciente, desde Macherey, se ha ocupado de subrayar las heterogeneidades y discontinuidades profundas de la obra de arte, que ya no se presenta de forma unificada u orgánica, sino prácticamente como un almacén de desperdicios o como un cuarto trasero para subsistemas disjuntos, impulsos de todo tipo y materiales en bruto dispuestos al azar (Jameson (1984), 1995: 72), estas descripciones serían el punto de partida para pensar la antipoesía como una lengua franca.

Y, del mismo modo, ¿hay una metodología antipoética? La antipoesía actuaría de este modo como un catalizador de hablas sociales y ejercería

29 Por ejemplo, en el hecho de que la crítica utilice la categoría de personaje y no de hablante para referirse al Cristo del Elqui. 
una importante tarea de revisión o "desautomatización de los discursivos" en momentos de crisis culturales.

\section{BIBLIOGRAFÍA}

Alonso, María Nieves. "Mi veterana se llamaba Clarisa y yo soy un simple predicador". Acta Literaria 25 (2000): 59-79.

Angenot, Marc. Teoría literaria. México: Siglo XXI, 1993.

Binns, Niall. Nicanor Parra o El arte de la demolición. Santiago: Editorial UV de la Universidad de Valparaíso, 2014.

Brunner, J. Joaquín. Un espejo trizado: ensayo sobre cultura y políticas culturales. Santiago: FLACSO, 1988.

Cohen, Jean. El lenguaje de la poesía: teoría de la poeticidad. Madrid: Gredos, 1982.

Culler, Jonathan. La poética estructuralista: el estructuralismo, la lingüística y el estudio de la literatura. Barcelona: Anagrama, 1978.

Deleuze, Gilles. El anti-Edipo: capitalismo y esquizofrenia. Barcelona: Paidós, 1985.

Fischer-Lichte, Erika. Semiótica teatral. Madrid: 1998.

Foxley, Carmen. Enrique Lihn: escritura excéntrica y modernidad. Santiago: Universitaria, 1995.

Galende, Federico. Vanguardistas, criticos y experimentales: vida y artes visuales en Chile, 1960-1990. Santiago: Metales Pesados, 2014.

Gottlieb, Marlene. "El monólogo dramático en la antipoesía de Nicanor Parra". Atenea 510 (2015): 23-39.

"Nicanor Parra o el método del discurso". Atenea 473 (1996): 71-94.

Grossman, Edith. The antipoetry of Nicanor Parra. New York: New York University Press, 1975.

Huneeus, Cristian. "Sobre la poesía de Parra". Mensaje 262 (1977): 491-498.

Jameson, Fredric. El posmodernismo o la lógica cultural del capitalismo avanzado. Barcelona: Paidós, 1991.

Lago, Tomás. "Luz en la poesía". Prólogo a Tres poetas chilenos. Santiago: Cruz del Sur, 1942.

Lihn, Enrique. "Doce años de escritura en todos los géneros". Anales de Literatura Chilena 16 (2011): 183-201.

Morales, Leonidas. "Nicanor Parra y el proyecto antipoético". Anales de Literatura Chilena, 2012. 2009.

Noguerol, Francisca. Contra el canto de la goma de borrar: asedios a Enrique Lihn. Sevilla: Secretariado de Publicaciones de la Universidad de Sevilla, 2005.

Olivárez, Carlos. Conversaciones con Jorge Teillier. Santiago: Los Andes, 1993. 
Open, Georg. Poesía, ensayo y entrevistas. Selección y traducción de Kurt Folch. Santiago: Ediciones Universidad Diego Portales, 2012.

Pacheco, José Emilio. "Menosprecio y alabanza de la poesía”. El espíritu del valle 2-3, 1987. Parra, Nicanor. Versos de Salón. Santiago: Nascimento, 1962.

Nicanor Parra Antipoems: New and selected. New York: New Directions, 1985. Temporal. Santiago: Ediciones de la Universidad Diego Portales, 2014.

Obras completas \& algo + (1935-1972); (1975-2006). Barcelona: Galaxia Gutenberg, 2006; 2011.

Pavis, Patrice. Teatro contemporáneo. Imágenes y voces. Santiago: ARCIS, LOM, 1998.

Saussure, Ferdinand de. Curso de lingüística general. Trad. Amado Alonso. Buenos Aires: Losada, 1945.

Schopf, Federico. El desorden de las imágenes. Huidobro, Neruda, Parra. Santiago: Universitaria, 2009.

“Advertencia preliminar". De Parra a nuestros días (Selección de Erwin Díaz). Santiago: Metales Pesados, 2005.

Del vanguardismo a la antipoesía. Santiago: Lom, 2000.

Soto, César. "Los libros de Nicanor Parra". Estudios Públicos 136, 2014.

Zurita, Raúl. Literatura, lenguaje y sociedad (1973-1983). Santiago: CENECA, 1983. 